\title{
Complete Cytogenetic Insight of Tho-Tho Cattle
}

Imusosang Longkumer ${ }^{1}$, Anupama Mukherjee ${ }^{2}$, Sarat Chandra Yenisetti ${ }^{1}$, Sabyasachi Mukherjee ${ }^{2}$ and Moonmoon $\mathrm{Mech}^{2}$

1. Department of Zoology, Nagaland University (Central), Lumami 798627, Nagaland, India

2. National Research Centre on Mithun, Jharnapani 797106, Nagaland, India

\begin{abstract}
To investigate the cytogenetic parameters and characterise the chromosomal banding pattern of Tho-Tho cattle, a breed of indigenous cattle found in the Northeastern states of India were reared for meat purpose. Lymphocyte culture technique was carried out in 28 Tho-Tho cattle and culture was harvested for good metaphase spread. Good metaphase spreads were selected for analysis, such as relative length, centromeric index and arm ratio. Centromeric banding (C-banding) and reverse banding (R-banding) methods were done for detail and better understanding of the chromosome morphology. The chromosome number in Tho-Tho cattle was observed to be $2 n=60$ in all complete metaphase. The mean relative length of the autosomal chromosomes varied from $5.48 \% \pm$ $0.107 \%$ to $1.79 \% \pm 0.105 \%$ in male and $5.31 \% \pm 0.148 \%$ to $1.86 \% \pm 0.055 \%$ in female, respectively. The chromosome banding showed C-positive dark band heterochromatin in all the acrocentric autosome. However, in sex chromosome, the Y-chromosome showed negative $\mathrm{C}$-band and also the $\mathrm{X}$-chromosome did not show any stain at the centromeric region. The numbers of R-band pattern were observed to be 490 and 499 band in male and female, respectively. One of the X-chromosome showed light banding pattern, confirming the inactivation during the embryonic development in female. The fundamental chromosome number and banding pattern of Tho-Tho cattle did not vary from the other breed of the Bos indicus. However, it is necessary to start a cytogenetic screening of the Tho-Tho cattle and expand upon more number to be kept at different villages of Nagaland in order to identify animals with chromosomal abnormalities, so that it can be excluded from future breeding strategies for conservation of Tho-Tho genetic resource.
\end{abstract}

Key words: Tho-Tho cattle, karyotype, cytogenetic analysis, chromosome banding.

\section{Introduction}

Tho-Tho cattle are black animal available in different hilly pockets of Nagaland and are considered as semi domesticated. They are found grazing in the forest and unlike other cattle they are very alert. The body of Tho-Tho cattle is mostly covered with short glossy hairs; coat colour is either pure black or black with white spot; neck is long and fine; horns are blackish and curved upward with pointed tips. Udder is small and hump is very prominent in this animal. The local people consider Tho-Tho cattle as a ceremonial animal of various social rituals. The total population of Tho-Tho cattle is estimated about 175,897 [1].

Tho-Tho cattle are known to the local people for

Corresponding author: Anupama Mukherjee, Ph.D., research fields: animal genetics and breeding. E-mail: writetoanupama@gmail.com. many centuries and have a significant distinct phenotype as compared to the other breeds of cattle due to geographical boundaries and environmental uniqueness. Since the traits are heritable in nature, it needs to be evaluated cytogenetically as well as at molecular level. A previous study on Tho-Tho cattle chromosome analysis with conventional Giemsa staining method has been reported [2]. However, no further reports have been made on chromosome banding techniques on this bovine species. Therefore, the present study was focused on the chromosome morphology, cytogenetic analysis and chromosome banding in this breed and also in selecting the animals with chromosomal abnormalities, if any, which might affect the productive and reproductive performance and overall herd economic loss. Ultimately, this will be useful for genetic conservation and propagation of Tho-Tho cattle. The output of the present study will be 


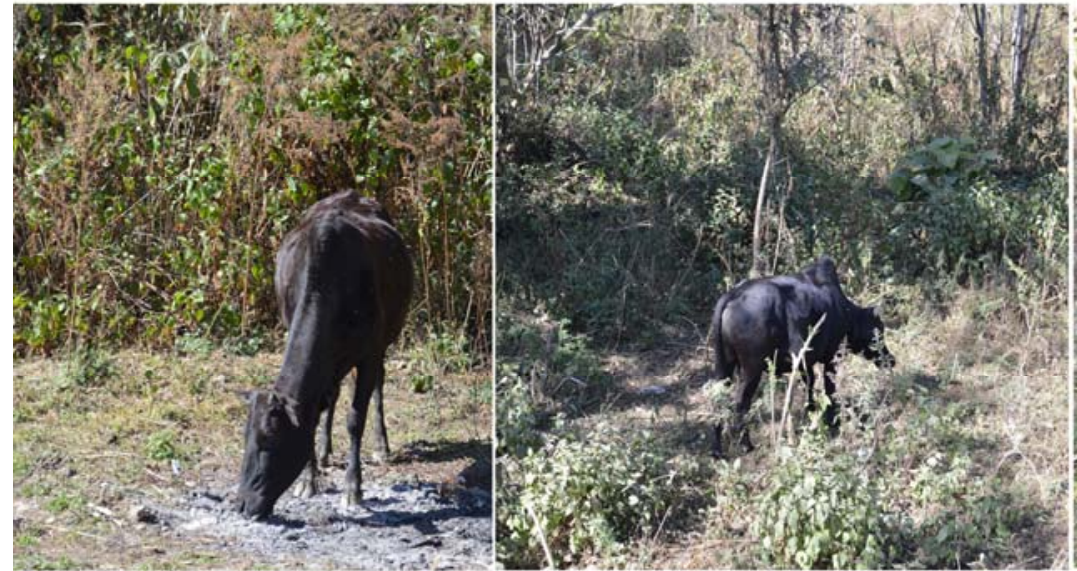

(a) (b)

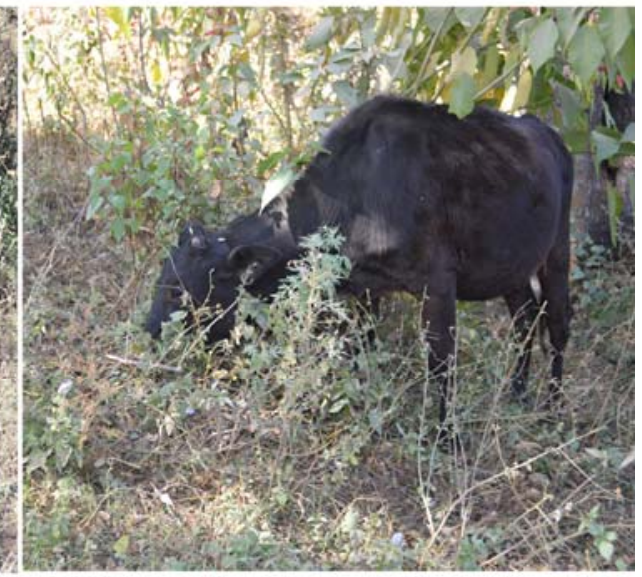

(c)

Fig. 1 Tho-Tho cattle licking ash (a), Tho-Tho bull in forest (b) and Tho-Tho eating leaves (c).

helpful for providing the basis for comparative analysis with the other breeds of Bos indicus (Fig. 1).

\section{Materials and Methods}

\subsection{Sample Collection}

The samples were collected from 17 males and 11 females of Tho-Tho cattle kept at the station farm of National Research Centre on Mithun, and the field samples were also collected from Visvema, Kidema, Merima and Kigwema all under Kohima district. The blood was collected following the guidelines suggested by animal ethics committee of the institute.

\subsection{Lymphocyte Culture and Harvesting}

The lymphocyte culture technique was applied and a volume of $0.5 \mathrm{~mL}$ blood was cultured in each tube containing $6 \mathrm{~mL}$ Ham's F-10 cell culture media, which was supplemented with $15 \%$ fetal calf serum and pokeweed mitogen at $2.5 \mu \mathrm{g} / \mathrm{mL}$ added with antibiotics penicillin and streptomycin, and incubated for $72 \mathrm{~h}$ at $37^{\circ} \mathrm{C}$ [3]. The culture tubes were shaken at 5-6 $\mathrm{h}$ interval for the uniform distribution of cell in the media. Two drops of colchicine $(100 \mu \mathrm{g} / \mathrm{mL})$ were added at $45 \mathrm{~min}$ prior to the harvesting of the culture. Harvesting was done by transferring the media into the centrifuge tube and was spun at $1,500 \mathrm{rpm}$ for 10 min. The supernatant was removed and the cell pellet was treated with pre-warm hypotonic solution $(0.075$ $\mathrm{M} \mathrm{KCl}$ ) and incubated at $37{ }^{\circ} \mathrm{C}$ in water bath for 25 min. Few drops of freshly prepared chilled fixative (glacial acetic acid and methanol, 3:1) were added to stop the action of hypotonic solution. The cell button was washed with fixative till the supernatant became clear in about four series of washing. The cell button was used for preparing the slide and air dried until it was stained. Slides were stained in $2 \%$ Giemsa for 30 min and screened under Nikon 90i microscope. The good metaphase spreads from the slide were selected and photographs were taken.

\subsection{Cytogenetic Analysis}

The measurements of chromosomes were done for identification and pairing of homologous chromosomes using Image-Pro Premier 9.1 software. According to the size, length and structure of chromosome, the karyotype was constructed. By the parameters for cytogenetic analysis, such as relative length, centromeric index, arm ratio and the size of chromosome, the proportionate share of different types of chromosome which contributed to the total genome were calculated. These parameters were used not only for the construction of karyotype and ideogram, but also were required for morphology description of the chromosome. 


\subsection{Banding Techniques}

For chromosomal banding (R-banding) during incubation, culture was incorporated with 5-bromo-2'-deoxyuridine (BrdU) at the rate of $100 \mu \mathrm{L}$ (12 ug) per culture and incubated for $8 \mathrm{~h}$ prior to harvesting. Subsequently, cultures were harvested in usual manners and slides were prepared by air-dry method. The slide was kept for aging for one week for R-banding. However, for C-banding, the normal cell culture harvest was aged for one week.

R-banding: the R-banding was carried out by taking the aged slides, then being treated with Hoechst-33258 dye solution (0.5\%) for $20 \mathrm{~min}$ and being rinsed with distilled water. It was mounted with $2 \times$ saline sodium citrate (SSC) and was exposed to fluorescence blue-black light in a dark chamber for 2 h. The slide was then stained with $2 \%$ Giemsa solution for $4 \mathrm{~min}$. The slides were observed under microscope and photograph was taken for further cytological analysis. In case of C-banding, the aged slides were treated with $0.2 \mathrm{~N} \mathrm{HCl}$ for $1 \mathrm{~h}$ at room temperature. Then it was treated with freshly prepared $\mathrm{Ba}(\mathrm{OH})_{2}$ for 3-5 min. The slides were then kept in Coplin jar containing $0.2 \mathrm{~N} \mathrm{HCl}$ at $56^{\circ} \mathrm{C}$ for 10 min to remove the traces of barium hydroxide crystals. It was followed by incubation in $2 \times \mathrm{SSC}$ for $1 \mathrm{~h}$ at $60{ }^{\circ} \mathrm{C}$ and stained by $2 \%$ Giemsa for $20 \mathrm{~min}$. The slide was then observed under microscope and further cytological analysis was done.

C-banding: in case of C-banding, the air-dried slides were taken and treated with $0.2 \mathrm{~N} \mathrm{HCl}$ for $1 \mathrm{~h}$ at room temperature. Then it was treated with freshly prepared $\mathrm{Ba}(\mathrm{OH})_{2}$ for $3 \mathrm{~min}$ at $55^{\circ} \mathrm{C}$. The slides were then kept in Coplin jar containing $0.2 \mathrm{~N} \mathrm{HCl}$ at $56^{\circ} \mathrm{C}$ for $10 \mathrm{~min}$ to remove the traces of barium hydroxide crystals. It was followed by incubation in $2 \times \mathrm{SSC}$ for $1 \mathrm{~h}$ at $60^{\circ} \mathrm{C}$ and stained by $2 \%$ Giemsa for $20 \mathrm{~min}$. The slide was then observed under microscope and good metaphase spread was selected and photographed. Karyotype of C-banding was prepared after arranging it according to the shape and size of the chromosome.

\section{Results}

The diploid chromosome number in Tho-Tho cattle was observed to be $2 n=60$ in all complete metaphase examined. The normal karyotype shows that all the autosomes are acrocentric chromosome; in sex chromosome, X-chromosome was sub-metacentric chromosome and $\mathrm{Y}$-chromosome was the smallest acrocentric chromosome (Fig. 2). The present finding is in agreement with the earlier reports [4] in indigenous cattle, and the karyotype investigation is being used for evolution of species as well as for comparison among species [5-7]. The cytogenetic studies were also used for screening the chiameric calves [8] and ruling out fertility problems in female [9].

Cytogenetic analysis was done for both male and female Tho-Tho cattle and found that the mean relative length in autosome ranged from $5.48 \% \pm$ $0.107 \%$ to $1.79 \% \pm 0.105 \%$ in male and $5.31 \% \pm$ $0.148 \%$ to $1.86 \% \pm 0.055 \%$ in female Tho-Tho, respectively. The parameters, like centromeric index and arm ratio on bi-armed X-chromosomes, were taken into account and calculated. The centromeric index in male was $36.45 \% \pm 0.31 \%$ and in female it was $31.06 \% \pm 0.55 \%$. The arm ratio was $2.60 \pm 0.09$ and $2.23 \pm 0.06$ for male and female Tho-Tho cattle, respectively. Therefore, the bi-armed X-chromosome is categorized as sub-metacentric chromosome, and referring to the value of the cytogenetic analysis, an ideogram was prepared. The present study found that the cytogenetic parameters of the Tho-Tho breed of cattle are in agreement with the other breeds Bos indicus, thus confirming that karyotype profile of investigated animals do not differ from standard karyotype of bovine species. However, the present study on chromosomes of Tho-Tho cattle will be a platform for further comparative studies with other breeds of same species by molecular cytogenetics and molecular techniques (Fig. 3, Table 1).

The C-banded metaphase chromosome showed a distinct dark stain at the centromeric region in all the 
acrocentric autosome. The centromeric region of the sub-metacentric chromosome, i.e., X-chromosome, did not show any stain. The density of the centromeric stain appears to be more in the larger chromosome and it reduces as the size of the acrocentric chromosome decreases. In Tho-Tho cattle, the Y-chromosome did not show banding pattern (C-negative) (Fig. 4).

The R-banding chromosome shows a series of strongly stained bands along the length of the chromosome. The numbers of R-positive bands are seen more in larger chromosomes and reduce as the size of the chromosome decreases in karyotype. The prominent bands are observed in the telomeric portion of all chromosomes. In female, the inactivation of $\mathrm{X}$-chromosome is clearly shown, as the $\mathrm{p}$ arm of one $\mathrm{X}$-chromosome shows no dark band and the $\mathrm{q}$ arm shows alternating dark bands and light bands. The R-positive dark bands are the approximate bands that can be observed. The present study found that the numbers of R-bands for Tho-Tho cattle were 496 and 499 in male and female, respectively (Fig. 5).

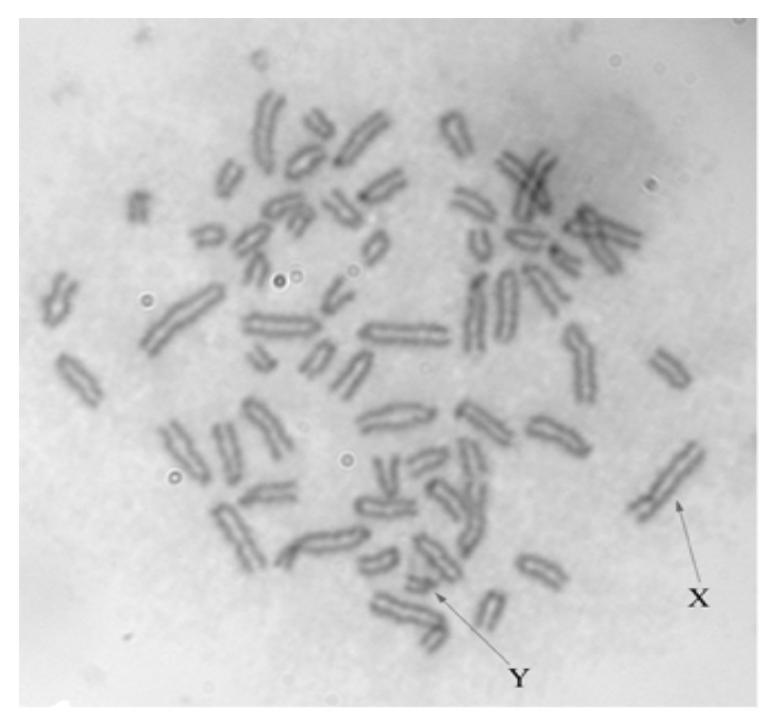

(a)

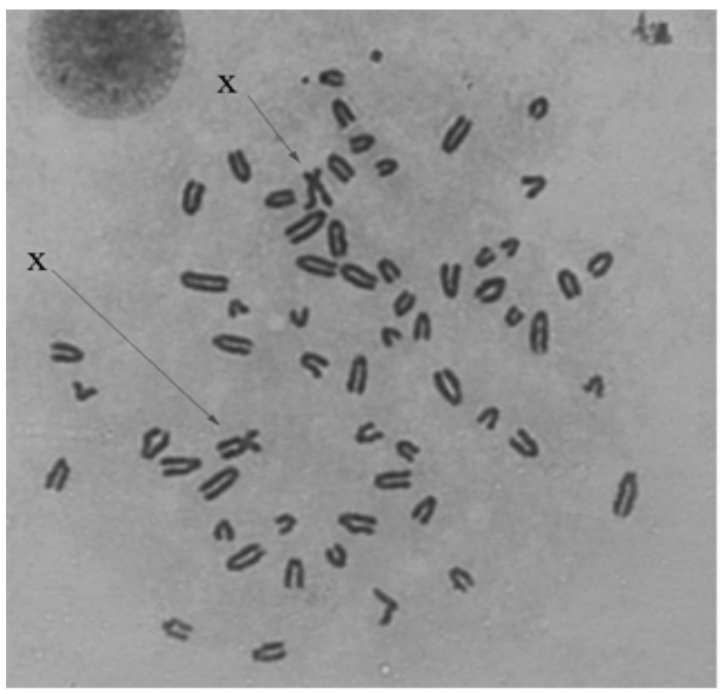

(c)

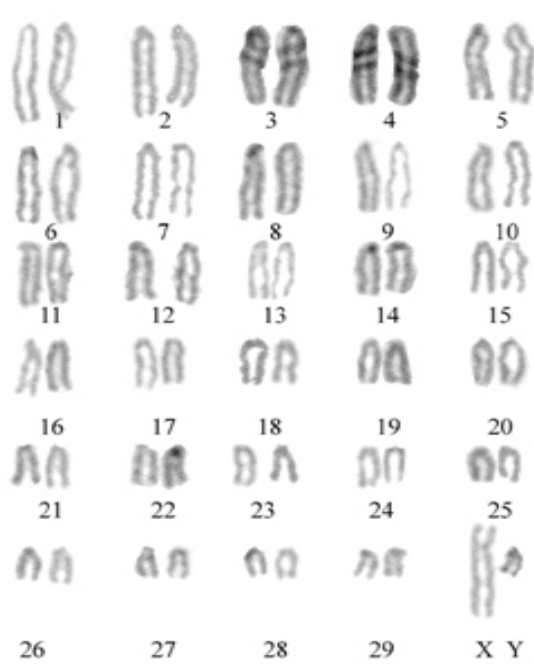

(b)

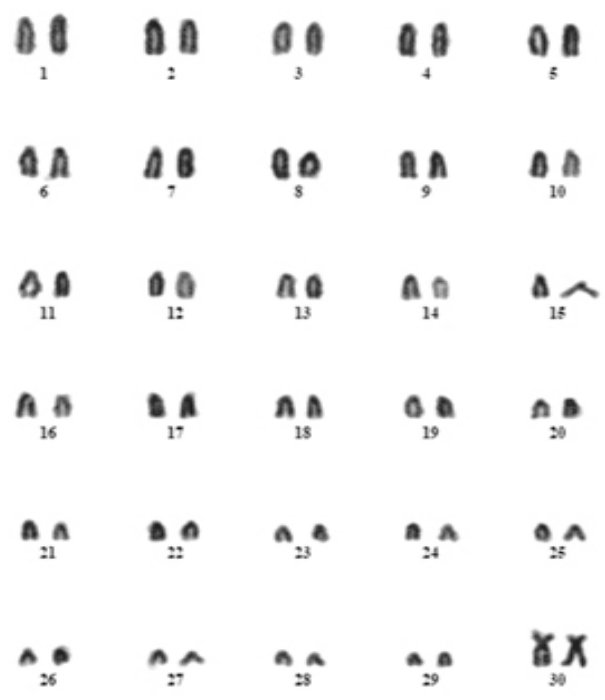

(d)

Fig. 2 Metaphase spread and karyotype of male (a, b) and female (c, d) Tho-Tho cattle. 


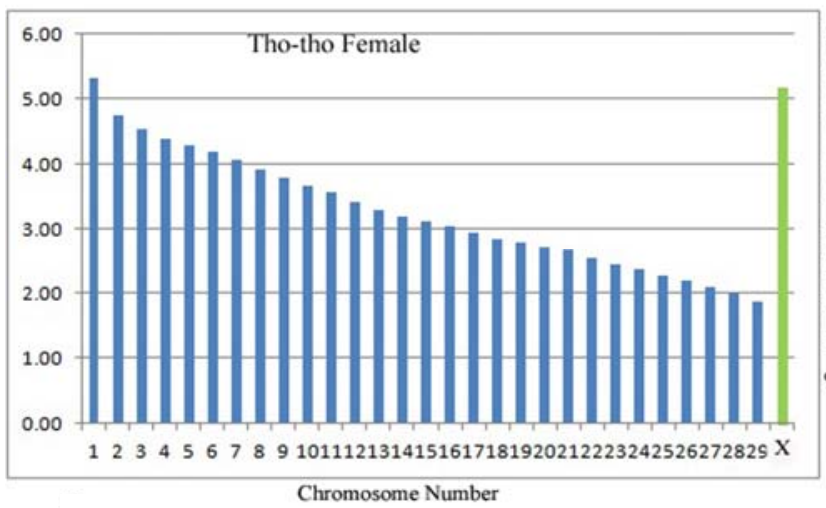

(a)

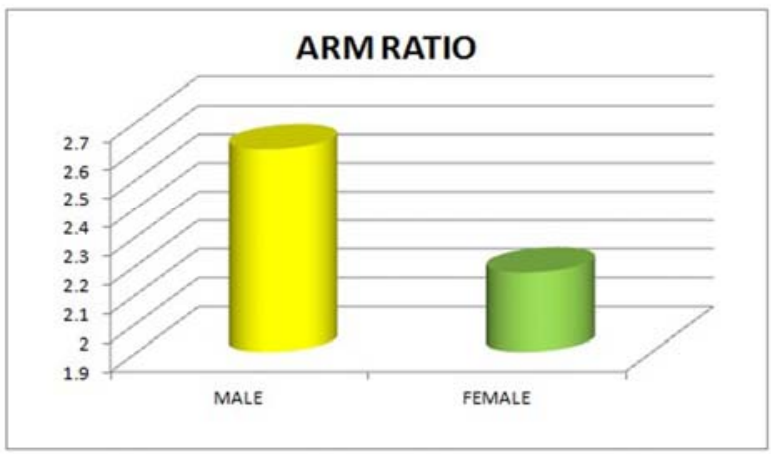

(c)

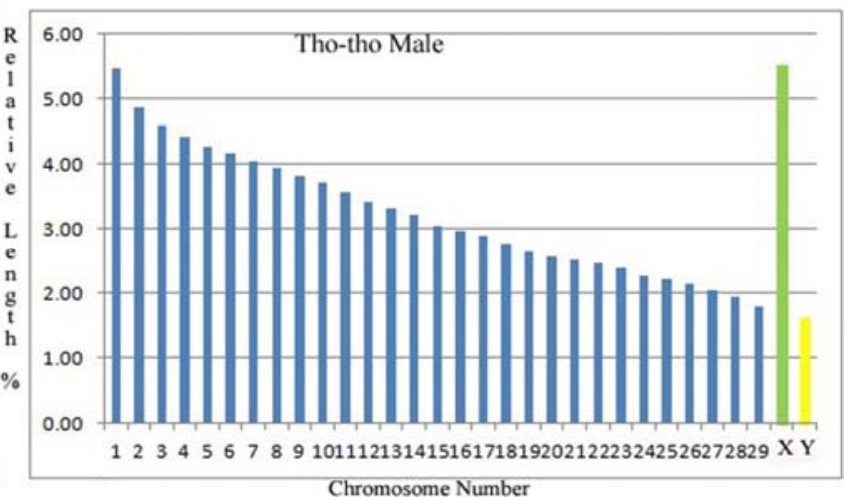

(b)

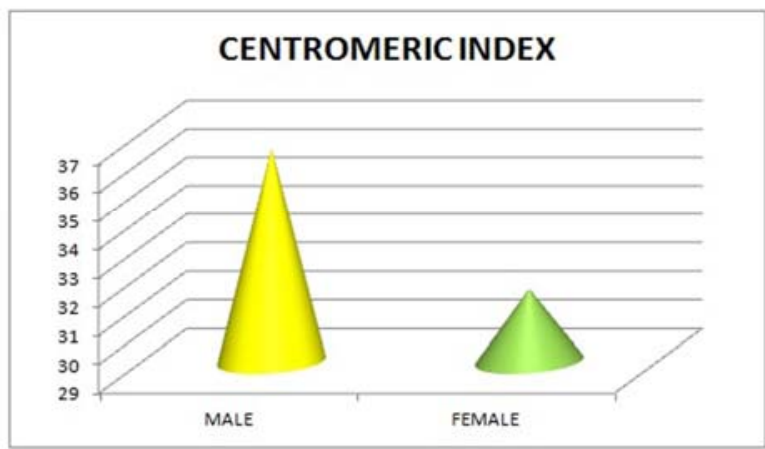

(d)

Fig. 3 Ideogram (a, b), arm ratio (c) and centromeric index (d) of female and male Tho-Tho cattle.

Table 1 Cytogenetic parameters of Tho-Tho cattle.

\begin{tabular}{|c|c|c|c|c|c|c|c|}
\hline \multirow{2}{*}{$\begin{array}{l}\text { Chromosome } \\
\text { number (pair) }\end{array}$} & \multicolumn{2}{|c|}{ Relative length (\%) } & \multirow[t]{2}{*}{ Chromosome type } & \multicolumn{2}{|c|}{$\begin{array}{l}\text { R-band (number per } \\
\text { chromosome pair) }\end{array}$} & \multicolumn{2}{|c|}{ C-band (+/-) } \\
\hline & Male (mean \pm SE) & Female (mean \pm SE) & & Male & Female & Male & Female \\
\hline 1 & $5.48 \pm 0.10$ & $5.31 \pm 0.14$ & $\mathrm{a}$ & 32 & 28 & + & + \\
\hline 2 & $4.86 \pm 0.08$ & $4.75 \pm 0.06$ & $\mathrm{a}$ & 29 & 28 & + & + \\
\hline 3 & $4.59 \pm 0.11$ & $4.55 \pm 0.05$ & $\mathrm{a}$ & 28 & 27 & + & + \\
\hline 4 & $4.42 \pm 0.10$ & $4.40 \pm 0.04$ & $\mathrm{a}$ & 24 & 23 & + & + \\
\hline 5 & $4.27 \pm 0.07$ & $4.29 \pm 0.05$ & $\mathrm{a}$ & 24 & 22 & + & + \\
\hline 6 & $4.16 \pm 0.09$ & $4.19 \pm 0.04$ & $\mathrm{a}$ & 24 & 20 & + & + \\
\hline 7 & $4.05 \pm 0.07$ & $4.06 \pm 0.03$ & a & 24 & 24 & + & + \\
\hline 8 & $3.93 \pm 0.04$ & $3.92 \pm 0.02$ & $\mathrm{a}$ & 21 & 24 & + & + \\
\hline 9 & $3.82 \pm 0.06$ & $3.78 \pm 0.04$ & $\mathrm{a}$ & 18 & 20 & + & + \\
\hline 10 & $3.73 \pm 0.04$ & $3.68 \pm 0.05$ & $\mathrm{a}$ & 19 & 20 & + & + \\
\hline 11 & $3.57 \pm 0.02$ & $3.57 \pm 0.03$ & a & 16 & 20 & + & + \\
\hline 12 & $3.42 \pm 0.02$ & $3.42 \pm 0.02$ & $\mathrm{a}$ & 16 & 16 & + & + \\
\hline 13 & $3.31 \pm 0.03$ & $3.29 \pm 0.03$ & $\mathrm{a}$ & 16 & 20 & + & + \\
\hline 14 & $3.21 \pm 0.02$ & $3.19 \pm 0.02$ & $\mathrm{a}$ & 16 & 16 & + & + \\
\hline 15 & $3.05 \pm 0.04$ & $3.11 \pm 0.02$ & $\mathrm{a}$ & 12 & 15 & + & + \\
\hline 16 & $2.96 \pm 0.03$ & $3.03 \pm 0.02$ & $\mathrm{a}$ & 16 & 16 & + & + \\
\hline 17 & $2.89 \pm 0.04$ & $2.94 \pm 0.03$ & $\mathrm{a}$ & 12 & 16 & + & + \\
\hline 18 & $2.77 \pm 0.05$ & $2.85 \pm 0.04$ & $\mathrm{a}$ & 12 & 13 & + & + \\
\hline 19 & $2.64 \pm 0.08$ & $2.80 \pm 0.05$ & a & 12 & 13 & + & + \\
\hline 20 & $2.57 \pm 0.07$ & $2.71 \pm 0.04$ & $\mathrm{a}$ & 12 & 12 & + & + \\
\hline 21 & $2.53 \pm 0.06$ & $2.66 \pm 0.04$ & $\mathrm{a}$ & 12 & 12 & + & + \\
\hline
\end{tabular}


(Table 1 continued)

\begin{tabular}{|c|c|c|c|c|c|c|c|}
\hline \multirow{2}{*}{$\begin{array}{l}\text { Chromosome } \\
\text { number (pair) }\end{array}$} & \multicolumn{2}{|c|}{ Relative length (\%) } & \multirow[t]{2}{*}{ Chromosome type } & \multicolumn{2}{|c|}{$\begin{array}{c}\text { R-band (number per } \\
\text { chromosome pair) }\end{array}$} & \multicolumn{2}{|c|}{ C-band (+/-) } \\
\hline & Male $($ mean \pm SE) & Female (mean \pm SE) & & Male & Female & Male & Female \\
\hline 22 & $2.48 \pm 0.07$ & $2.54 \pm 0.05$ & $\mathrm{a}$ & 12 & 12 & + & + \\
\hline 23 & $2.40 \pm 0.07$ & $2.44 \pm 0.05$ & a & 12 & 8 & + & + \\
\hline 24 & $2.27 \pm 0.08$ & $2.36 \pm 0.06$ & a & 12 & 10 & + & + \\
\hline 25 & $2.22 \pm 0.08$ & $2.26 \pm 0.05$ & a & 9 & 12 & + & + \\
\hline 26 & $2.13 \pm 0.09$ & $2.18 \pm 0.06$ & a & 4 & 8 & + & + \\
\hline 27 & $2.03 \pm 0.08$ & $2.09 \pm 0.06$ & $\mathrm{a}$ & 8 & 8 & + & + \\
\hline 28 & $1.95 \pm 0.10$ & $1.99 \pm 0.05$ & a & 8 & 8 & + & + \\
\hline 29 & $1.79 \pm 0.10$ & $1.86 \pm 0.05$ & a & 8 & 8 & + & + \\
\hline $\mathrm{X}$ & $5.53 \pm 0.22$ & $5.18 \pm 0.11$ & $\mathrm{Sm}$ & 20 & 20 & - & - \\
\hline $\mathrm{Y}$ & $1.63 \pm 0.05$ & & $\mathrm{a}$ & 2 & & - & \\
\hline
\end{tabular}

a: acrocentric; Sm: sub-metacentric; +: present; -: absent.

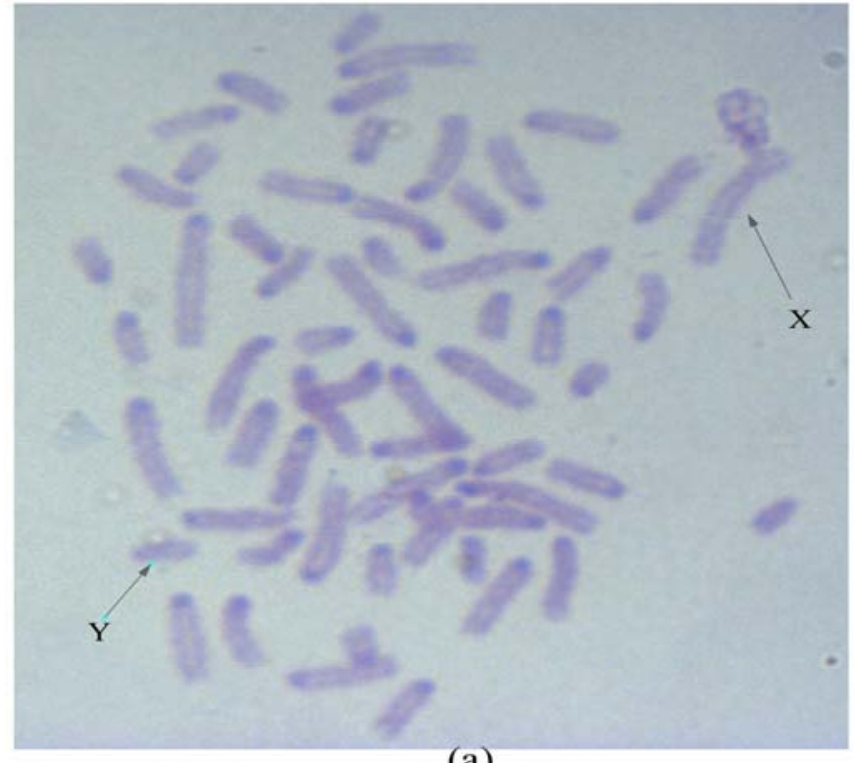

(a)

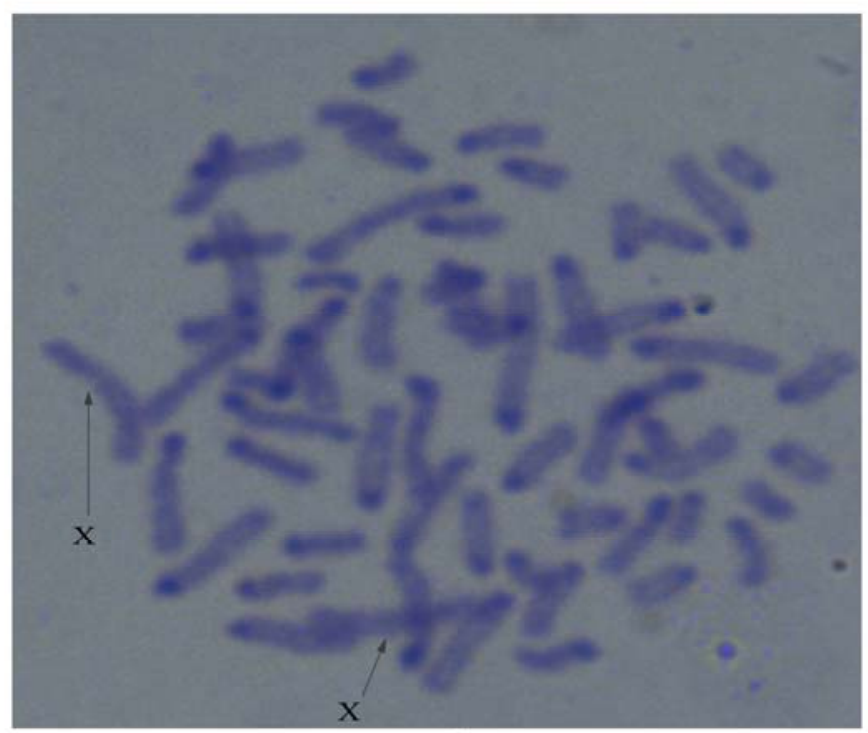

(c)

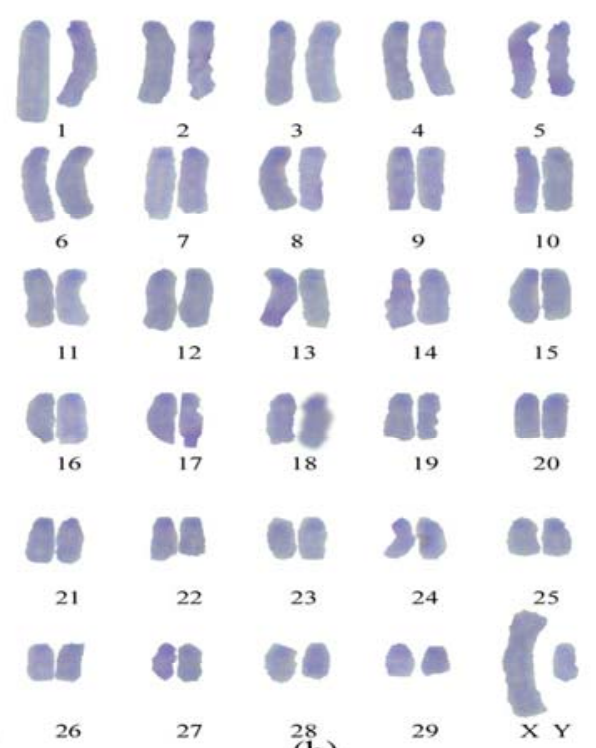

(b)

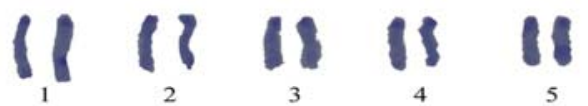

$\begin{array}{lllll}11 & 11 & 11 & 4 & 11 \\ 6 & 4 & 9 & 10\end{array}$

$\begin{array}{lllll}\text { (1) } & 11 & 11 & \text { |1 } & \text { |1 } \\ 11 & 12 & 13 & 14 & 15\end{array}$

11 is is 11 II

$\begin{array}{lllll}16 & 17 & 18 & 19 & 20\end{array}$

110118018

$\begin{array}{rrrrr}21 & 22 & 23 & 24 & 25 \\ 26 & 27 & 28 & 29 & \mathrm{x} \times\end{array}$

(d)

Fig. 4 C-banded metaphase spread and C-banded karyotype of male (a, b) and female (c, d) Tho-Tho cattle. 


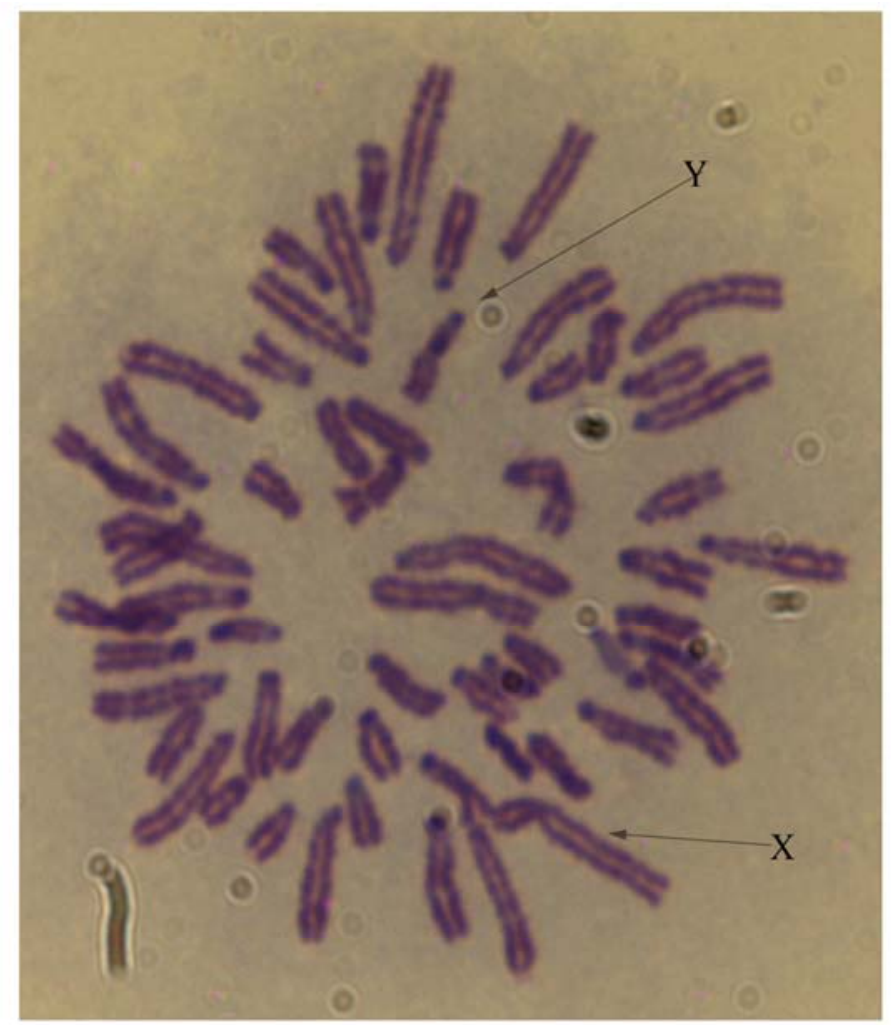

(a)

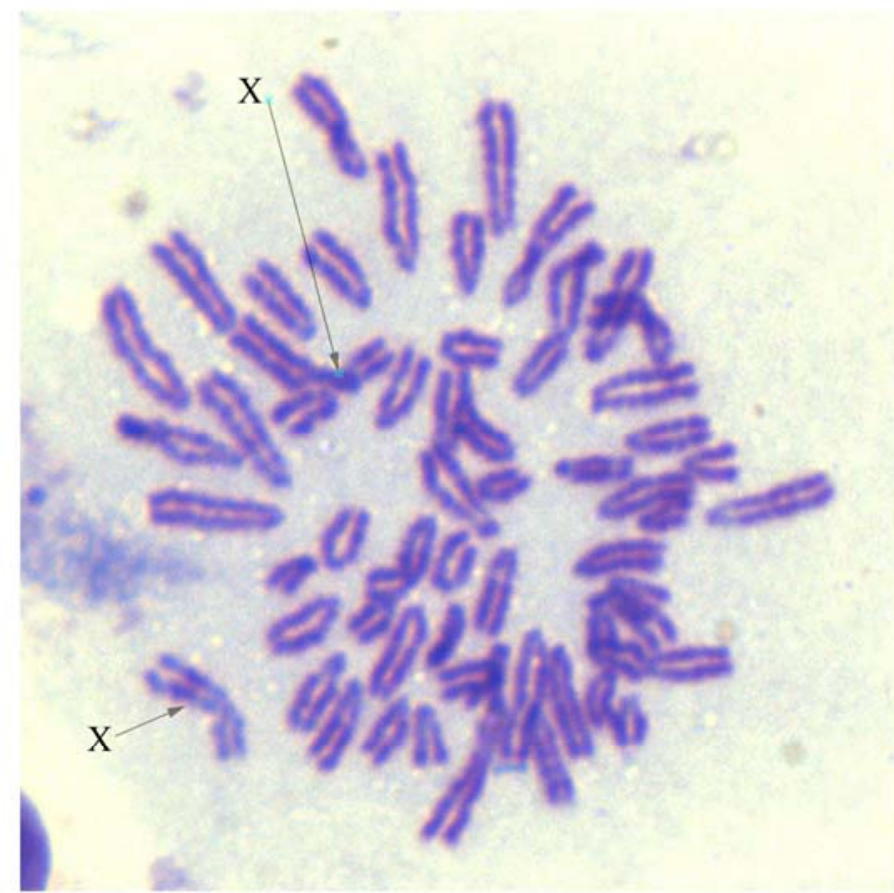

(c)

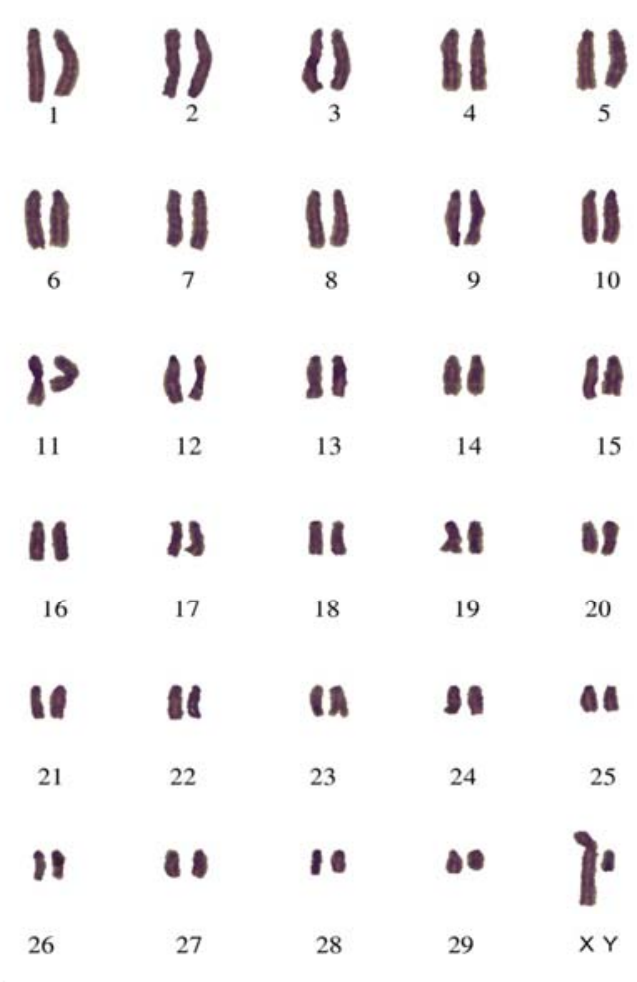

(b)

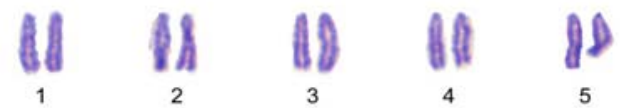

81 If 18 \& 40

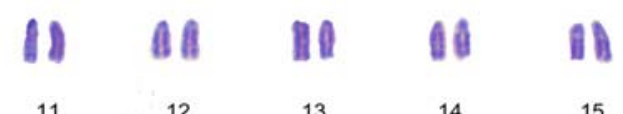

OA Al in 10 in

\begin{tabular}{|c|c|c|c|}
\hline 16 & 17 & 18 & 19 \\
\hline Rt & $0 A$ & $8 A$ & $\Delta A$ \\
\hline 21 & 22 & 23 & 24 \\
\hline$A$ A & 14 & 10 & 60 \\
\hline 26 & 27 & 28 & 29 \\
\hline
\end{tabular}

(d)

Fig. 5 R-banded metaphase spread and R-banded karyotype of male (a, b) and female (c, d) Tho-Tho cattle. 


\section{Discussion}

The report on chromosome number of Tho-Tho cattle $(2 n=60)$ is in agreement with the earlier report on normal chromosome number of various breeds of Bos indicus [10-12]. The size of the chromosome variation in autosome was uniformly descending as presented in the karyotype. This can be categorised into a set of first nine pairs of chromosome as large, followed by next 10 pairs as medium and the last 10 pairs of autosome as small size chromosomes as observed in other cattle [13, 14]. The variation of relative length in autosome in Tho-Tho cattle was found to be similar with that of Deoni cattle breed - an indigenous breed belongs to Western India. The largest chromosome in the genome was chromosome 1, which is similar to Thai's native cattle, unlike that of Deoni and Umblachery cattle breed where $\mathrm{X}$-chromosome is the largest in the genome [13]. Standard value for centromeric index is $25 \%-37.5 \%$ and $25.1 \%-40 \%$, according to Levan et al. [15] and Gurrea [16], respectively. Similarly, standard value of arm ratio is 1.67-3 and 1.50-2.99, according to Levan et al. [15] and Gurrea [16], respectively, which add up to the confirmation of X-chromosome being sub-metacentric.

The centromeric banding technique showed that the entire acrocentric chromosome exhibited the dark bands (C-positive) on the centromeric region; the result was in agreement with Umblachery breed of cattle [12]. In sex chromosome, there were no dark bands on the $\mathrm{X}$-chromosome like all the other breeds of cattle. The negative C-banding pattern of $\mathrm{Y}$-chromosome in Tho-Tho cattle is in agreement with the species specific banding pattern of the Bos indicus [17].

The R-banding pattern of the Tho-Tho cattle showed about 500 band level with 490 in male and 499 in female, respectively. The present finding supports the earlier R-banding in cattle by at 500 band level [18]. The chromosome banding pattern on this particular Tho-Tho cattle confirms that there was not much variation from the other breed of the same species.

\section{Conclusions}

The study on the chromosomal diversity and morphology in Tho-Tho cattle was done, since this breed is having the habitat in Northeastern region of India that is remotely located from the habitat of all other descript breed and the history of domestication is also not very far. Thus, it is required to study the chromosomal profile so that scientific and systematic breeding strategies can be followed. It is also necessary to start a cytogenetic screening of the Tho-Tho and expand upon more numbers to be kept at different villages of Nagaland in order to identify animals with chromosomal abnormalities, so that it can be excluded from future breeding strategies for conservation of Tho-Tho genetic resource.

The diploid chromosome number in Tho-Tho cattle was observed to be 60 in all complete metaphase spreads. The normal karyotype showed that all autosomes are acrocentric; whereas, X-chromosome was sub-metacentric and Y-chromosome was the smallest acrocentric. The chromosome banding revealed the presence of heterochromatin with dark banding pattern at the centromeric region of all autosome. However, Y-chromosome and $\mathrm{X}$-chromosome did not show any band. The R-banding pattern showed the banding pattern at 500 band level, which was similar to the standard banding pattern described earlier in other breed of Bos indicus. However, the accumulation of characters and genetic variation in nature is a long process and it is difficult to detect. Therefore, further analysis on these cattle is suggested by using various molecular cytogenetic techniques, such as fluorescent in-situ hybridization (FISH) and molecular technique, which may reveal the variations of Tho-Tho cattle from other Bos indicus breeds.

\section{Acknowledgments}

The present study is a part of the Ph.D. thesis work of the first author. Special thanks to the Rajiv Ghandi 
National Fellowship Funding Agency, University Grants Commission, for providing Ph.D. fellowship. The authors would like to acknowledge the lab mates for constant moral support from start to end of the research work.

\section{References}

[1] Choudhury, H., Sarmah, V. B., Dhali, A., Choudhury, M. D., Vidyarthi, V. K., Kumar, S., Baruah, U. K., and Sarma, D. K. 2014. "Chromosomal Characteristics of Tho-Tho Cattle (Bos indicus) in Nagaland, India." African J. Agri. Res. 9 (38): 2893-9.

[2] Longkumer, I., Yenisetti, S. C., Mukherjee, A., Mukherjee, S., Mech, M., Rongmei, J., and Rajkhowa, C. 2012. "Karyological Studies on Tho-Tho (Bos indicus): An Indigenous Cattle of Nagaland." Int. J. Bio-Resource and Stress Management 3 (4): 433-6.

[3] Yadav, B. R., and Balakrishnan, C. R. 1985. "Modified Medium for Lymphocyte Culture for Chromosome Studies in Livestock." Indian J. Dairy Sc. 38: 50-3.

[4] Iannuzzi, L., and Di Meo, G. P. 1995. "Chromosomal Evolution in Bovids: A Comprison of Cattle, Sheep and Goat G- and R-Banded Chromosomes and Cytogenetic Divergences among Cattle, Goat and River Buffalo Sex Chromosomes." Chromosome Res. 3 (5): 291-9.

[5] Amarante, M. R. V., Tsuribe, P. M., Jorge, W., and Rocha, G. P. 2000. "Chromosome Analysis of Cattle and Horses.” Bra. J. Vet. Res. Anim. Sci. 37 (4): 296-8.

[6] Mamat-Hamidi, I. I., and Hilmi, M. 2009. "Karyotype of Malayan Gaur (Bos gaurus hubbacki), Sahiwal-Friesian Cattle and Gaur $\times$ Cattle Hybrid Backcrosses." Pak. J. Biol. Sci. 12 (12): 896-901.

[7] De Lorenzi, L., Planas, J., Rossi, E., Malagutti, L., and Parma, P. 2015. "New Cryptic Karyotypic Differences between Cattle (Bos taurus) and Goat (Capra hircus)." Chromosome Res. 23 (2): 225-35.

[8] Biswas, J., Biswas, S., Pan, S., and Mondol, A. 2015. “A Cytogenetic Study of Heterosexual Quadruplets of Cattle (Bos indicus)—A Case Report." Veterinarski Arhiv 85 (1):
105-10.

[9] Khatun, M. R., Arifuzzaman, M., and Ashraf, A. 2011. "Karyotype for Identification of Genetic Abnormalities in Cattle." Asian J. Anim. Vet. Adv. 6 (2): 117-25.

[10] Kosarcic, S., Kovacs, A., Kosarcic, D., Suvajdzic, L., Kovacevic, M., Kapetanov, M., Milanov, D., and Zivkov Balos, M. 2005. "Chromosome Changes in Cattle on the Farms in Serbia." Genetika 37 (1): 15-23.

[11] Balaji, R., Gupta, B. R., Narasimha, R. G., and Narasa, R. G. V. 2006. "Cytogenetic Characterization of Deoni Cattle.” Indian J. Anim. Res. 40 (1): 20-4.

[12] Kumarasamy, P., Sivaselvam, S. N., Rajendran, R., Thangaraju, P., and Mahalinga-Nainar, A. 2008. "Chromosomal Characterization of Umblachery Breed of Cattle (Bos indicus) - A Famous South Indian Breed of Tamilnadu, India.” Indian J. Sc. Tech. 1 (6): 1-3.

[13] Popescu, C. P., Long, S., Riggs, P., Womack, J., Schmutz, S., Fries, R., and Gallagher, D. S. 1996. "Standardization of Cattle Karyotype Nomenclature: Report of the Committee for the Standardization of the Cattle Karyotype." Cytogenet. Cell Genet. 74 (4): 259-61.

[14] Jantarat, S., Tanomtong, A., Kakampuy, W., Kaewsri, S., and Buranarom, K. 2009. "Standardized Karyotype and Idiogram of Thai's Native Cattle Bos indicus (Artiodactyla, Bovidae) by Convention Staining, G-Banding, C-Banding and NOR-Banding Techniques." Thai J. Genet. 2 (2): 164-74.

[15] Levan, A., Fredga, K., and Sandberg, A. A. 1964. "Nomenclature for Centromeric Position on Chromosomes." Hereditas 52 (2): 201-20.

[16] Gurrea, M. D. S. 1986. "Reviewing the Chromosome Nomenclature of Levan et al..” Brazilian J. Genet. 9 (4): 741-3.

[17] Potter, W. L., Upton, P. C., Cooper, J., and Blackshaw, A. W. 1979. "C- and G-Banding Patterns and Chromosomal Morphology of Some Breeds of Australian Cattle." Aust. Vet. J. 55 (12): 560-7.

[18] Iannuzzi, L., Di Moe, G. P., Perucatti, A., and Ferrata, L. 1990. "A Comparison of G- and R-Banding in Cattle and River Buffalo Prometaphase Chromosome." Caryologia 43: $283-90$ 